\title{
Nonlinearities and Real Exchange Rate Dynamics
}

\section{Jean Imbs}

London Business School and CEPR

Haroon Mumtaz

London Business School
Morten O. Ravn

London Business School and CEPR

Hélène Rey

Princeton, CEPR, and NBER

\begin{abstract}
We confirm the presence of substantial nonlinearities in real exchange rate dynamics at the sectoral level. There exists zones where arbitrage is not profitable because of transaction costs, and thus mean reversion is inexistent. We compute the speed of mean reversion of sector specific real exchange rates, conditional on the existence of arbitrage as implied by our nonlinear estimations, and relate them to plausible economic determinants such as tradability and exchange rate volatility. (JEL: F36, F41, C43)
\end{abstract}

\section{Introduction}

The Law of One Price (LOP) states that prices of tradeable goods can differ across markets only to the extent that transactions costs or other impediments to arbitrage offset the profit opportunities arising from cross-market price differentials. In its aggregate version the LOP gives rise to Purchasing Power Parity (PPP) provided all goods are tradable and expenditure weights are identical across markets. Yet despite the simplicity of these principles, the empirical evidence points towards sizeable and very persistent price differentials across markets. In a now classic survey, Rogoff (1996) concludes that the consensus view on the half-life of real exchange rates is between three and five years. ${ }^{1}$

Acknowledgments: We thank Philippe Bacchetta, Jacques Mélitz, and participants in the EEA 2002 Annual Meetings in Venice for helpful comments. This paper is part of the project "Exchange Rates, International Relative Prices, and Macroeconomic Models" funded by the ESRC (grant no. L138 25 1043). This work is also part of a research network on "The Analysis of International Capital Markets: Understanding Europe's Role in the Global Economy," funded by the European Commission under the Research Training Network Program (Contract No. HPRN(ECT(E1999(E00067).

E-mail addresses: Imbs: jimbs@london.edu; Mumtaz: hmumtaz@london.edu; Ravn: mravn@ london.edu; Rey: hrey@princeton.edu

1. This view is mostly based on panel data estimations since univariate methods have typically failed to reject nonstationarity in real exchange rates. Exceptions include studies using very long time series or hyperinflationary environments. In another paper, we argue that controlling for parameter heterogeneity in dynamic panels substantially reduces the estimate of the half-life, to around one year, with a 95 percent confidence interval of five to twenty-four months. See Imbs, Mumtaz, Ravn, and Rey (2002). 
This paper takes the view that the speed of mean reversion contains information, for instance in the way it varies across different goods. In particular, we estimate various empirical models for relative prices allowing for the existence of transactions costs, and attempt to identify the determinants of these costs across different sectors. The starting point of our analysis is that transactions costs may give rise to non-linearities in the dynamics of relative prices, an insight that dates back at least to Heckscher's commodity points. Nonlinearities arise because transactions costs make arbitrage unprofitable in response to small deviations from the LOP, and therefore relative prices do not revert to the mean, while sufficiently large price-differentials lead to arbitrage and thus to mean reversion.

Many theories of international price differences implicitly rely upon the existence of transactions costs. The presence of nominal rigidities, for example, implies that relative prices expressed in a common currency are related to variations in nominal exchange rates. This implies the existence of some impediments to arbitrage, i.e., of some (broadly defined) transactions costs. Similarly, firms may wish to price differently across different locations but this, again, requires there be no arbitrage across different market segments.

Our main contribution is to use direct estimates of arbitrage costs to inform the issue of price differences across markets. Arbitrage costs are in all likelihood goods- or at least industry-specific. Thus a disaggregate approach should contain valuable information on the determinants of those costs. In this paper, we examine the sources of persistent international sectoral price differentials using nonlinear modeling; in particular, we estimate Threshold Autoregressive (TAR) models at the sectoral level. ${ }^{2}$ The TAR model assumes there may be a zone of price differentials for which there is no (or little) tendency for mean reversion, while outside of this zone relative prices are mean-reverting. This allows us to derive an estimate of the effective transactions costs, as well as the speed of mean reversion contingent upon being in the arbitrage zone.

A strand of recent papers have applied nonlinear models to disaggregated data, with more of an emphasis on the power of stationarity tests than the present work. ${ }^{3}$ Our objective is different: we use the cross-sectoral dispersion in the width of the estimated arbitrage bands, as well as the cross sectoral dispersion in the speeds of mean reversions, conditional on the existence of arbitrage, to uncover the determinants of international market segmentation. Our work is therefore closely linked to Obstfeld and Taylor (1997), who provide some evidence that transactions costs may be related to distance, tariffs, and exchange rate uncertainty. We are however the first ones to investigate whether models

2. The literature has instead largely focused on estimating nonlinear models for the aggregate real exchange rates; see e.g., Panos, Nobay, and Peel (1997), Sarantis (1999), Taylor and Peel (2000), Taylor, Peel, and Sarno (2001), or Kilian and Taylor (2002). For theoretical analyses on nonlinearities in real exchange rate dynamics see Dumas (1992) and Sercu and Uppal (2000).

3. See in particular O'Connell and Wei (2002) or Sarno, Taylor, and Chowdury (2002). 
with nonlinear dynamics help accounting for both the determinants of transactions costs and the conditional speeds of mean reversion. ${ }^{4}$

\section{Data and Econometric Issues}

We examine monthly two-digit sectoral non-harmonized price indices for thirteen countries and for nineteen different goods categories. The data comes from Eurostat, the statistical agency of the European Union. We examine the period 1975-1996, for which we have full coverage for most of the goods and countries in the sample. ${ }^{5}$

The goods categories contain a mixture of low and high unit costs goods (e.g., bread vs. vehicles), highly tradeable goods (e.g., clothing), goods commonly regarded as nontraded (public transport or hotels), and goods for which there is a wide variation in the degree of product differentiation (fuel vs. sound and photographic equipment). We include goods customarily labeled "nontradeable," because these may be informative about the nature of transactions costs.

We use the United States as the anchor country, a choice guided by the fact that the U.S. dollar has floated against all the other currencies in our sample throughout the period considered. ${ }^{6}$ We examine (2-digit) goods level prices defined as $q_{j t}^{i}=\ln \left(P_{j t}^{i} \cdot E_{t}^{i} / P_{j t}^{U S}\right)$ where $P_{j t}^{i}$ denotes the price of good $j$ in country $i$, at date $t$, and $E_{t}^{i}$ is the nominal exchange rate between country $i$ 's currency and the U.S. dollar.

\subsection{Nonlinearities}

We follow Obstfeld and Taylor (1997) and estimate so-called threshold autoregressive (TAR) models for the relative prices. These models allow for thresholds effects, and thus potentially for the existence of different regimes in the dynamic behavior of relative prices. We assume that relative prices follow stochastic processes of the form

$$
\Delta q_{j t}^{i}=\left\{\begin{array}{l}
\sum_{k=1}^{K} \beta_{j}^{i, o u t}(k)\left(q_{j t-k}^{i}-c_{j}^{i}\right)+e_{j t}^{i, \text { out }} \text { if } q_{j t-d}^{j}>\left|c_{j}^{i}\right| \\
\sum_{k=1}^{K} \beta_{j}^{i, i n}(k) q_{j t-k}^{i}+e_{j t}^{i, i n} \text { if } q_{j t-d}^{j} \leq\left|c_{j}^{i}\right|
\end{array}\right.
$$

4. Transactions costs may also be important for a host of other puzzles in international economics. Obstfeld and Rogoff (2000) argue that they may help resolve six major puzzles in international economics. Ravn and Mazzenga (forthcoming) examine these issues in a fully-fledged international business cycle model with flexible prices.

5. The countries are Belgium, Denmark, Finland, France, Germany, Greece, Ireland, Italy, Netherlands, Portugal, Spain, the United Kingdom, and the United States. The goods are Bread, Meat, Dairy, Fruits, Tobacco, Drinks, Clothing, Footwear, Rents, Fuel, Furniture, Domestic Appliances, Vehicles, Public Transport, Communications, Sound, Leisure, Books, and Hotels.

6. Using the Pound Sterling as the numeraire gives virtually the same results. 
This is known as a TAR $(K, 2, d)$ model where 2 refers to the fact that there are two thresholds. We assume that the thresholds are symmetric and that the dynamics of the process outside the threshold are the same regardless of whether prices happen to be higher in the United States or in the other country. In what follows we make the simplifying assumption that $\beta^{i n}(k)=0, k=1, \ldots, K$, so that the process follows a random walk for $q_{j t-1}^{j} \in[-c ; c]$, i.e., when transaction costs outweigh the benefits of arbitrage.

The models are identified using the procedure described in Hansen (1997). We select the lag length via the Schwarz Criterion defined in Franses and Van Dijk (2000). The delay parameter $d$ is then chosen using a grid search as suggested in Hansen (1997). The model is estimated for $d=1, \ldots, 6$ and the delay that minimises the sum of squared residuals is chosen. Hansen's (1997) F-test is implemented to test for linearity and the null hypothesis is rejected if the probability value is below 10 percent.

There are two possible reasons why we may reject the existence of nonlinearities. The first one is that the threshold is sufficiently small and we may simply assume $c_{j}^{i}=0$ : we observe mean reversion in the whole domain and the process is stationary. The other possibility, however, is that $c_{j}^{i}>0$ but in-sample price differences never actually make it outside of the threshold bands. In this case as well, we cannot reject linearity and the process is nonstationary. In principle, stationarity tests should be helpful in distinguishing these two casessince relative prices should be stationary in the former yet nonstationary in the latter case. In practice this turns out to be difficult, due to the low power of unit root tests in small samples. In what follows we will experiment with different assumptions on how to distinguish between these two possibilities.

\subsection{The Determinants of Cross-Sectoral Relative Price Dynamics}

Based on the estimates of the dynamic models we investigate whether key aspects of the relative price processes can be related to goods and country specific variables. To do this, we run cross-sectional regressions explaining the key parameters from the estimations of (1). In particular, we conjecture

$$
\begin{gathered}
c_{j}^{i}=\lambda_{j}^{i}+\sum_{s=1}^{S} \phi_{j}^{i}(s) y_{j}^{i}(s)+\varepsilon_{j}^{i} \\
\ln T_{j}^{i}=\gamma_{j}^{i}+\sum_{s=1}^{S} \mu_{j}^{i}(s) z_{j}^{i}(s)+\varepsilon_{j}^{i}
\end{gathered}
$$

where $y_{j}^{i}$, and $z_{j}^{i}$ are vectors of explanatory variables. In equation (2) we investigate whether the estimated thresholds, which indicate the width of the arbitrage band, are related to variables reflecting transaction costs. In equation (3), we estimate the determinants of the conditional speed of mean reversion. $T_{j}^{i}$ 
denotes the estimated half-life (in months). The half-life is estimated from the impulse response function and defined as the period at which the impulse response is equal to half of the maximum response of the process (constraining this period to be strictly larger than the period at which the maximum impact occurs).

Our right-hand side variables attempt to capture the size and nature of transactions costs, as well as differences in market structure. The first proxy for transactions costs is distance, measured in (thousands of) kilometers between New York and the corresponding countries' capitols. We also include nontariff barriers, as measured by an indicator variable constructed by the OECD and the Office of the U.S. Trade Representative in the EU, a somewhat crude "dummy" variable. Our third explanatory variable is the volatility of the nominal exchange rate which can be thought of as reflecting uncertainty, playing an important role in models with fixed costs. Fourth, we examine the effects of a "tradeability" index measured by the sum of exports and imports to industry output for a given country. This is indicative of "unmeasured transactions costs," as it reflects effective intensity of trade linkages. Fifth, we include tariffs, as measured by the OECD. Finally, we add a measure of "intra-industry trade" for each country computed as a standard Grubel-Lloyd index, using the Eurostat international trade data. This measure is usually assumed to reflect product differentiation (and thus the extent of imperfect competition). Product differentiation can be understood as a type of transactions costs between imperfectly substitutable goods.

In equation (3) we include all of the preceding variables as well as two additional ones. First, the number of firms obtained from the UNIDO database as a proxy for competition. ${ }^{7}$ Second, sector specific inflation rates, assuming sectors with more average inflation are less prone to price rigidities and therefore may experience faster adjustment in relative prices.

\section{Results}

\subsection{Evidence on Nonlinearities}

We find nonlinearities for a large number of goods in the sample, i.e., no fewer than 117 of the 171 relative prices. Hence, the threshold autoregressive models appear to provide a better description of the dynamic properties of relative prices than standard linear autoregressive processes in a wide majority of cases. Furthermore, the evidence on non-linearities is not equally strong among different types of goods. For example, we find nonlinearities for goods such as vehicles, fuel, and sound equipment. These goods are either highly differenti-

7. To be precise, UNIDO does not report the number of firms, but rather the number of establishments. 


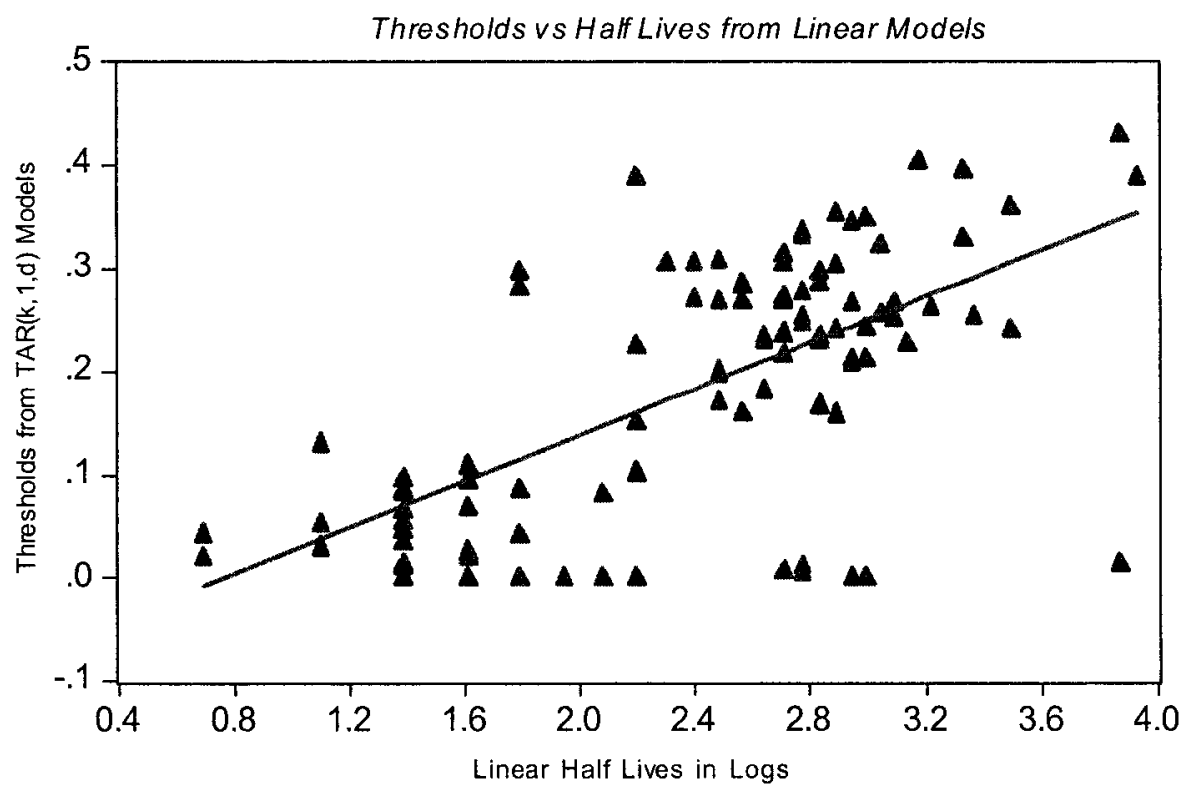

FIGURE 1. Thresholds versus Half Lives from Linear Models

ated or goods that are traded but for which transportation costs are nontrivial. But linearity is harder to reject for goods such as leisure or rent. In these latter cases, rejection of nonlinearity is likely to come from the nontradeability of the goods: arbitrage bands are so large that we never see mean reversion.

We do not present all the estimates due to space constraints, ${ }^{8}$ but two interesting results are worth mentioning. The estimated thresholds are higher for goods with largest estimated persistence when using standard linear autoregressive models. Furthermore, the reductions in sectoral half-lives, once nonlinearities are allowed for, are positively correlated with the half-lives obtained using a linear model. We show this in Figures 1 and 2 where we illustrate the estimated thresholds plotted against the half-lives based on linear autoregressive models (Figure 1), and the reduction in the half-lives (the half-life in the "outer" regime less the half-life based on a linear specification) plotted against the linear half-lives (Figure 2). This is how nonlinear models may lead to large reduction in the estimates of the overall persistence of the data as other researchers have documented.

\subsection{Explaining the Estimated Thresholds}

The first issue we examine is whether the estimated thresholds relate to standard measures of transaction costs. Using equation (2), we investigate this relation-

8. Detailed tables are available upon request. 


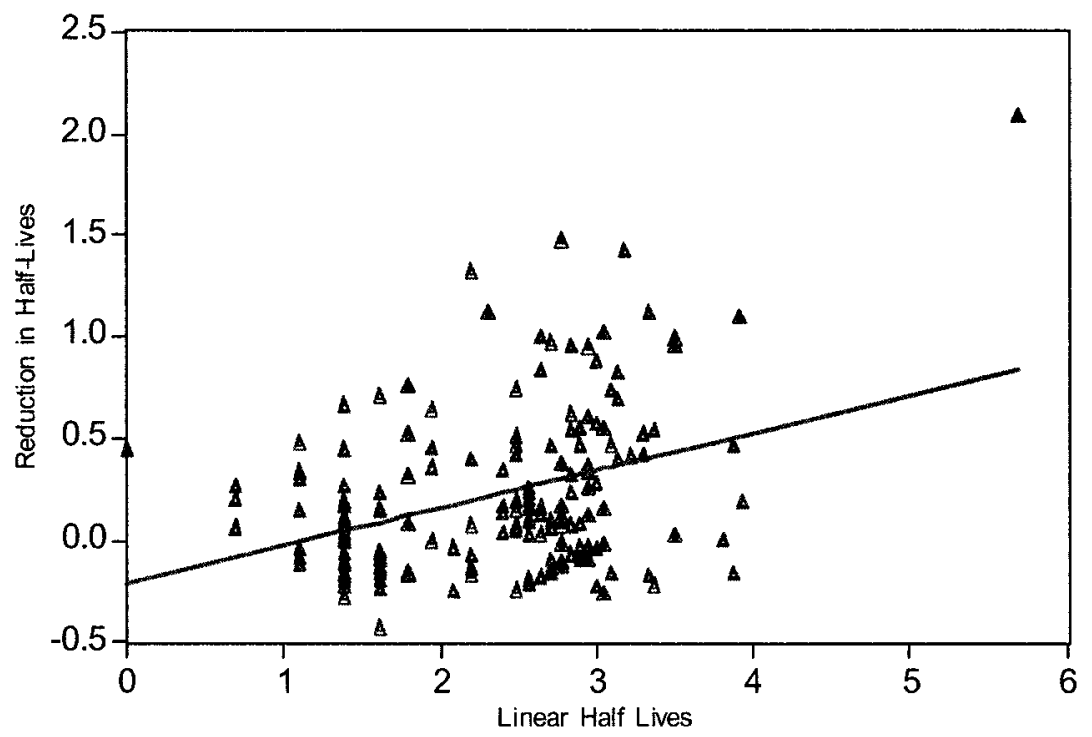

FIGURE 2. Reduction in Half-Lives versus Linear Half-Lives

ship with a Tobit estimator setting $c_{j}^{i}=0$ for those goods for which we could not reject linearity (columns (1) and (2) of Table 1). We then set $c_{j}^{i}=0$ only for those goods where both nonlinearity and stationarity are rejected (columns (3) and (4) of Table 1). We look at these two cases separately to check for the robustness of our results, given the low power of unit root tests in small samples.

We find that the two key determinants of the size of the estimated thresholds are (a) distance, and (b) nominal exchange rate volatility. Both of these variables are significant at very high confidence levels in our two specifications. We find that the larger the distance between markets, the higher is the threshold. This result is in line with standard wisdom: market segmentation and distance are positively correlated due to transportation and informational costs, which are

TABle 1. Threshold Regressions

\begin{tabular}{lcccc}
\hline & \multicolumn{2}{c}{ Nonlinear only } & \multicolumn{2}{c}{ Nonlinear and stationary } \\
\hline & $(1)$ & $(2)$ & $(3)$ & $(4)$ \\
Intra-Industry trade (IIT) & -0.0783 & $-0.1170^{*}$ & -0.0191 & - \\
Tradeability & $0.0574^{*}$ & - & 0.0141 & - \\
Nontariff barriers (NTB) & -0.0946 & - & 0.0056 & - \\
Distance & $0.5712^{* *}$ & $0.5412^{* *}$ & $0.5014^{* * *}$ & $0.5695^{* * *}$ \\
Exchange rate volatility & $0.9849^{* * *}$ & $0.8911^{* * *}$ & $1.2990^{* * *}$ & $0.9628^{* * *}$ \\
Tariffs & -0.0088 & - & 0.0176 & - \\
\hline$\overline{\mathrm{R}}^{2}$ & 0.1259 & 0.0997 & 0.2989 & 0.2673 \\
$\mathrm{~N}$ & 92 & 122 & 57 & 101 \\
Log L & -14.97 & -28.33 & 41.64 & 62.08 \\
\hline
\end{tabular}


Table 2. Half-Life Regressions

\begin{tabular}{|c|c|c|c|c|c|c|c|c|}
\hline & (1) & (2) & (3) & (4) & (5) & (6) & (7) & (8) \\
\hline IIT & -0.0565 & - & 0.2816 & 0.6263 & 0.2234 & & 0.1697 & \\
\hline NTB & 0.1412 & - & 0.1647 & $0.3945^{*}$ & $0.3796^{*}$ & $0.3547^{*}$ & 0.1596 & $0.2727 *$ \\
\hline Distance & $3.6370 * * *$ & $4.1867 * * *$ & $4.3257 * *$ & $4.0073^{* * * *}$ & $2.7886^{* *}$ & $3.2752 * * *$ & $3.3513^{* * * *}$ & $3.2637 * * *$ \\
\hline Inflation & 0.3852 & - & -0.0876 & & 0.1663 & & 0.1344 & \\
\hline Tariffs & -0.0277 & - & 0.1401 & & 0.0842 & & 0.0627 & \\
\hline$\overline{\mathrm{R}}^{2}$ & 0.3719 & 0.3987 & -0.0667 & 0.1085 & 0.0749 & 0.1617 & 0.2456 & 0.3370 \\
\hline $\mathrm{N}$ & 87 & 108 & 46 & 62 & 85 & 106 & 85 & 165 \\
\hline
\end{tabular}

both plausibly increasing with distance. ${ }^{9}$ Nominal exchange rate volatility is also highly significant. This may reflect the extent of uncertainty. In models with fixed costs, uncertainty plays an important role in limiting arbitrage. An important implication of our results is that exchange rate stabilization may be associated with lower relative price persistence.

Apart from these variables, we also find that intra-industry trade and tradeability may be related to the size of the arbitrage band. Somewhat surprisingly, however, we find that a larger fraction of intra-industry trade is associated with lower thresholds, a finding that contradicts the view that firms differentiate their goods across markets in order to increase their ability to price discriminate. We also find that tradeability increases the threshold. However, none of these two results is robust: they both disappear when we focus on the nonlinear and stationary cases.

Hence, the thresholds seem to be mainly determined by two key transactions cost variables, distance and exchange rate volatility. Like Obstfeld and Taylor (1997), we do not find any impact of non-tariff bareers on estimated thresholds. However, while the aforementioned authors find some relationship between tariffs and thresholds, we fail to uncover such a link. This may be due to the difficulties in measuring these variables accurately.

\subsection{What Determines the Persistence of Relative Prices?}

The second part of our analysis concerns the determinants of relative price persistence. We base this investigation on the cross-sectional regressions of the half-lives [equation (3)]. In order to see how nonlinearities matter, we compare the results with those obtained using linear models. The results of this exercise are reported in Table 2.

In the first two columns we examine the determinants of the speed of mean reversion based on linear autoregressive models. The half-lives are determined

9. See in particular Rauch (2001), Loungani, Mody, and Razin (2002) for the importance of information costs in goods trade. 
by distance, exchange rate volatility, the tradeability of the goods and the degree of competition. However, while the first three variables come out with the expected sign, the number of firms in the industry (our measure of competition) seems to imply longer half-lives, a result that contradicts standard economic theory. In the third and fourth columns we look at the conditional speed of mean reversion in sectors where we find nonlinearities. The results are to some extent similar to those from the linear models: distance and exchange rate volatility are important determinants of half-lives. But the coefficients on exchange rate volatility are much smaller than for the linear model. This may be due to the fact that higher exchange rate volatility is also associated with larger thresholds, which compounds the effect on the overall persistence of relative prices. ${ }^{10}$ The tradeability variable is also significant. Within the group of prices for which we find nonlinearities, however, larger tradeability is associated with longer halflives, which is counterintuitive. We also find that the measure of nontariff barriers is significant and positively correlated with the half-lives, as suggested by theory. Finally, we also notice that the number of firms (which came out with the wrong sign in the linear regressions) is no longer significant.

In columns (5)-(8) we investigate the determinants of the half lives using the appropriate models. In particular, when we have evidence on nonlinearities, we use TAR estimates, but simple linear autoregressive models when we could not reject linearity. The difference between columns (5) and (6) on the one hand and columns (7) and (8) on the other, is that in the latter we include a dummy variable in sectors where we could not reject linearity. This allows for possible differences in the means of the half-lives across the two samples. In columns (5) to (8), the results once again imply that the transactions costs proxies are the most important determinants of the speed of mean reversion. Measures of goods market competition (intra-industry trade and the number of firms) or measures of price stickiness (goods level inflation rates) are not any more significant here than in the previous section. Distance and nominal exchange rate volatility are in all cases key and very robust determinants of the speed of mean reversion. The estimated coefficients are however smaller than in the linear case, perhaps for similar reasons. Tradeability is significant with the expected sign when we look at all cases but not when we control for linearity. We also find that nontariff barriers appear to be related to longer half-lives although the evidence is weaker than for distance and exchange rate volatility.

\section{Conclusion}

We find strong evidence of non linearities in the dynamics of sectoral real exchange rates, as predicted by economic models incorporating some form of market segmentation. Prices mean revert only to the extent that deviations from

10. We note, however, that the same effect does not seem to apply to the distance variable. 
the law of one price are substantial, i.e., when benefits of arbitrage outweigh the trading frictions. Barriers to arbitrage may be caused by trading costs (e.g., transportation costs, informational costs, menu costs) or market structure (e.g., price discrimination, product differentiation, degree of competition). Using TAR models, we summarize the extent of barriers to arbitrage by two key parameters: the threshold (width of the arbitrage band) and the half-life (speed of mean reversion conditional on being in the zone where arbitrage is profitable). We show that both the threshold and the half-life are strongly positively related to distance and exchange rate volatility in all our specifications. Lower nontariff barriers are also correlated with less persistent deviations from the law of one price but the evidence is weaker. The strength of the distance and volatility variables suggests that barriers to arbitrage have more to do with trading costs per se than with product differentiation and industrial concentration. It would be of great interest to see whether this result holds for a different set of countries and whether a change in monetary regime such as EMU had a sizable effect on the dynamic of relative sectoral prices across Europe. Finally the considerable sectoral heterogeneity that we uncover in relative price dynamics has important implications. In particular, Imbs, Mumtaz, Ravn, and Rey (2002) show that previous studies have systematically overestimated the degree of persistence of the real exchange rate by failing to control for the heterogeneity of the speed of mean reversion of prices across different sectors. When we correct for that aggregation bias, our estimates for the half-life of the real exchange rate fall dramatically.

\section{References}

Dumas, Bernard (1992). "Capital Market Equilibrium and the Real Exchange Rate in a Spatially Separated World," Review of Financial Studies, 5(2), 153-180.

Franses, Philip Hans and Dick van Dijk (2000). Non-Linear Time Series Models in Empirical Finance, July, Cambridge University Press.

Hansen, Bruce (1997). "Inference in TAR models," Studies in Nonlinear Dynamics and Econometrics.

Imbs, Jean, Haroon Mumtaz, Morten Ravn, and Helene Rey (2002). "PPP Strikes Back: Aggregation and the Real Exchange Rate," mimeo National Bureau of Economic Research, working paper no. 9372.

Kilian, Lutz and Mark Taylor (2002). "Why It Is So Difficult to Beat the Random Walk Forecast of Exchange Rates?," mimeo European Central Bank.

Loungani, Prakash, Ashoka Mody, and Assaf Razin (2002). "The Global Disconnect: The Role of Transactional Distance and Scale Economies in Gravity Equations," Scottish Journal of Political Economy, 49(5).

O'Connell, Paul G. J., and Shang-Jin Wei (2002). "The Bigger They Are, the Harder They Fall." Journal of International Economics, 56, pp. 21-53.

Obstfeld, Maurice and Kenneth Rogoff (2000). "The Six Major Puzzles in International Macroeconomics: Is There a Common Cause?" NBER Macroeconomics Annual.

Obstfeld, Maurice, and Alan M. Taylor (1997). "Nonlinear Aspects of Goods-Market Arbitrage and Adjustment: Heckscher's Commodity Points Revisited." Journal of the Japanese and International Economies, 11, pp. 441-479. 
Panos, Michael, A. Robert Nobay, and David A. Peel (1997). "Transactions Costs and Nonlinear Adjustment in Real Exchange Rates: An Empirical Investigation." Journal of Political Economy, 105(4), pp. 862-879.

Rauch, J. (2001). "Business and Social Networks in International Trade." Journal of Economic Literature, 39, pp. 1177-1203.

Ravn, Morten O. and Elisabetta Mazzenga (n.d.). "International Business Cycles: The Quantitative Role of Transportation Costs." Journal of International Money and Finance, forthcoming.

Rogoff, Kenneth S. (1996). “The Purchasing Power Parity Puzzle.” Journal of Economic Literature, 34, pp. 647-668.

Sarantis, Nicholas (1999). "Modeling Non-Linearities in Real Effective Exchange Rates." Journal of International Money and Finance, 18, pp. 27-45.

Sarno, Lucio, Mark P. Taylor, and Ibrahim Chowdury (2002). "Non-Linear Dynamics in Deviations from the Law of One Price." CEPR Discussion paper No. 3377.

Sercu, Piotr and Raman Uppal (2000). Exchange Rate Volatility: Trade and Capital Flow under Alternative Exchange Rate Regimes. Cambridge: Cambridge University Press.

Taylor, Mark P. and David A. Peel (2000). Nonlinear Adjustment, Long-Run Equilibrium and Exchange Rate Fundamentals." Journal of International Money and Finance, 19, pp. $33-53$.

Taylor, Mark P., David A. Peel, and Lucio Sarno (2001). "Nonlinear Mean-Reversion in Real Exchange Rates: Towards a Solution to the Purchasing Power Parity." International Economic Review, 42(4), pp. 1015-1042. 